\title{
O habitus \\ e o nada
}

\section{RESUMO}

Neste artigo, 0 autor considera e analisa duas teorias, a de Sartre e a de Bourdieu, em relação ao objeto de pesquisa: 0 sujeito e sua dimensão fenomenológica.

\section{ABSTRACT \\ In this paper the author compares Sartre's and Bourdieu's theories about both the subject and his phenomenologic dimension.}

PALAVRAS-CHAVE (KEY WORDS)

- Bourdieu

- Sartre

- 0 sujeito (The subject)
Clóvis de Barros Filho

Cásper Líbero - ESPM - ECA/USP
O habitus e o nada: um ensaio sobre as ilusões cruzadas

$S_{E}$ "Deus morreu" (Nietzsche) no século XIX, "o sujeito ressuscitou" (Deleuze) no final do século $X X$. Talvez para substituílo. Após ter sido despersonificado, "transformado em um simples lugar, onde se encontram linhas de causalidade históricas, socioeconômicas, lingüísticas ou pulsionais"1, normatizado pela objetividade do enunciado e manipulado pela passividade da recepção, o grande retorno do sujeito tem um palco: o do campo da comunicação, do agir comunicativo, dos meios, das mediações, da impossibilidade de não comunicar.

O objeto último deste trabalho é o sujeito e sua dimensão fenomênica: a ação. Serão consideradas e analisadas duas teorias distintas (talvez antagônicas): a de Sartre e a de Bourdieu. Mais concretamente, a crítica deste último ao primeiro. Partimos da hipótese teórica da influência, por "efeito de campo", do existencialismo de Sartre na fundamentação filosófica da sociologia de Bourdieu.

Sartre é desigualmente citado, analisado e criticado por Bourdieu em seus principais trabalhos ${ }^{2}$. O ponto mais visível de incompatibilidade entre a sociologia de Bourdieu e a filosofia de Sartre está na origem social das disposições constitutivas do habitus, de um lado, e a teoria da consciência secundada pelos conceitos de nadadização ${ }^{3}$ do passado, de liberdade existencial, de projeto original e de má-fé que dela decorrem, de outro.

Não raro, as críticas a um autor são classificáveis em metodológicas e substantivas ou doutrinárias. Neste caso, ambas coincidem, ou se mostram inexoravelmente interdependentes. Afinal, ao inscrever Sartre na sua sociologia, isto é, ao analisar as condições propriamente 
sociais que permitiram e ensejaram a obra do filósofo, Bourdieu já se contrapõe ao primado subjetivista do existencialismo sartriano ${ }^{4}$.

A crítica de Bourdieu a Sartre apresenta duas características gerais: de um lado, ela é inseparável da discussão do método fenomenológico, que serviu a este último como suporte epistemológico. De outro, ao discutir os pressupostos subjetivistas de Sartre, Bourdieu marca diferenças em relação às inúmeras críticas marxistas a este autor.

No que concerne ao método fenomenológico, Bourdieu observa que a sua especificidade consiste em "colocar entre parênteses" a realidade do projeto intencional (redução transcendental). Esta wessenchau toma como ponto de partida os dados imediatos da experiência vivida, exigindo, para tanto, do observador uma suspensão, uma ruptura em relação às experiências passadas. Pretende, através deste procedimento, alcançar a essência do que é observado (redução eidética). Esta suspensão confere ao método fenomenológico um novo tipo de legitimidade, inédita no campo filosófico, relacionada à proximidade de seus ritos com as exigências (ou aparências) de objetividade científica, denominadas na fenomenologia de evidências apodíticas.

Assim, para Bourdieu, o método fenomenológico não pode ir além de uma descrição do que caracteriza a experiência "vivida" do mundo social, isto é, a apreensão deste mundo como evidente, como allant de soi. Sendo assim, o pensamento fenomenológico exclui a questão das condições de possibilidade desta experiência, isto é, as condições materiais, propriamente sociais, que a tornam possível. No entanto, apesar de denunciar o "espontaneismo ingênuo" do método fenomenológico, a crítica de Bourdieu não se confunde com as reflexões marxistas sobre o tema, vistas por ele como "reducionistas" ou trop simplistes.

Para Bourdieu, a filosofia é uma manifestação ideológica que, como qualquer outra, apresenta uma singularidade, isto é, sua evolução não é sempre paralela à das outras manifestações ideológicas. Afinal, os filósofos, enquanto pertencentes a um espaço cada vez mais específico e autônomo de relações, com seus troféus, regras e estratégias próprias, se dão por objeto as questões últimas da existência e do conhecimento.

Assim, o estudo da filosofia de Sartre, objetivada em discursos como pretensões de universalidade, deve ter por objeto a trajetória de sucessivas posições ocupadas pelo autor no campo filosófico francês e europeu, o que equivale dizer as suas tomadas de posição, sempre reflexivas, indicativas de estratégias internas ao campo ${ }^{5}$.

Todo campo, e o campo filosófico se inscreve nesta espécie de regra geral de funcionamento, ativa uma forma específica de interesse, uma illusio específica como reconhecimento tácito do valor dos objetos em disputa no jogo e como domínio prático das regras que o regem. Este interesse específico, que é implícito à participação no jogo, varia em função da posição, propriamente filosófica, ocupada em relação a dos demais posições e, também, em função da trajetória (história das posições) que conduz cada filósofo a esta posição ${ }^{\text {. }}$.

Segundo esta ótica reflexiva, Bourdieu destaca a oposição específica a Sartre freqüentemente constituída por filósofos "de origem popular ou interiorana, deslocados em relação às tradições escolares francesas e vinculados a instituições universitárias periféricas (...)". Esses filósofos, no entanto, "ofereciam uma alternativa a todos aqueles que, por razões diversas, pretendiam reagir contra a imagem, ao mesmo tempo fascinante e refutada, do intelectual total, presente em todas as frentes de pensamento"7.

Esta prerrogativa inerente à lógica dos campos de definir estratégias em função de posições não é exclusiva dos 
dominados. O próprio Sartre, na sua célebre conferência L'existentialisme est un humanisme, começa situando-se em relação aos demais, marcando posições, definindo adversários e respondendo a eles. Os trechos abaixo deixam claro esta preocupação: "Uns e outros nos acusam de (...) considerar que o homem está isolado, em grande parte, aliás, porque nós partimos, dizem os comunistas, da subjetividade pura, isto é, do je pense cartesiano, ou ainda, do momento em que o homem se alcança na solidão (...)"8.

Ainda no Existentialisme, Sartre ironiza: "Acusam-nos de aprisionar o homem na sua subjetividade individual", ou, "nosso ponto de partida é, de fato, a subjetividade do indivíduo, e isto por razões estritamente filosóficas. Não porque somos burgueses, mas porque queremos uma doutrina baseada na verdade". . Sempre arrolando acusações de que se sente direta ou indiretamente vítima, Sartre destaca em La transcendance de l'ego que "os teóricos da extrema esquerda acusaram muitas vezes a fenomenologia de ser um idealismo e de afogar a realidade no fluxo das idéias"10.

Desta forma, o uso do conceito de campo e a autonomia relativa do campo filosófico em relação a qualquer outro campo discrimina as críticas de Bourdieu das inúmeras análises de pensadores marxistas sobre a denominada "filosofia burguesa". Para estes, os filósofos, inscritos numa relação de dominação de classe, se afastam dos problemas econômicos, políticos e sociais em função dos limites traçados pela burguesia à filosofia.

Assim, a título de exemplo, na condição de crítico marxista do existencialismo, Lukacs ${ }^{11}$ observa que "não faltam construções utópicas propondo a transformação da cultura, até mesmo por meios revolucionários como em Nietzsche. Mas este último critica severamente os sintomas culturais da divisão capitalista do trabalho sem sugerir, em momento algum, qualquer transformação da organização social”.

Como podemos inferir, para Bourdieu, a progressiva autonomização do campo filosófico e sua lógica de tomadas de posição e deslocamentos reflexivos são instrumentos sociológicos mais eficazes (do que a "luta de classe" e a "dominação" e a "hegemonia" burguesa) para a definição do dizível e do não dizível em filosofia.

Desta forma, apoiando-nos na lógica sistêmica, que explica e possibilita as ações e acomodações (reações) que delas decorrem, constatamos que a principal crítica de Bourdieu a Sartre é o seu "ultrasubjetivismo"12. Assim, mesmo sem aceitar, como vimos, as apelações de "marxista" e "teórico de extrema esquerda"13, mesmo sem admitir, em momento algum de sua reflexão, o caráter "determinista" do habitus, Bourdieu joga o jogo e ocupa a posição de um atacado por Sartre (anacronismos à parte).

Nesta perspectiva de confronto, Sartre e Bourdieu propõem, ambos, uma crítica ao senso comum. Uma inversão do pensamento ordinário. Essas propostas, no entanto, partem de premissas contraditórias entre si sobre esse senso comum e, conseqüentemente, sustentam teses opostas. Explicando melhor: tanto Bourdieu quanto Sartre consideram as pessoas iludidas porque desconhecem a real causa de seus comportamentos. Só que ilusão e realidade, nas duas doutrinas, desempenham papéis trocados. Assim, Bourdieu denuncia uma ilusão calculadora (I); enquanto Sartre, uma ilusão determinista (II).

\section{Ilusão calculadora ${ }^{14}$}

Toda ilusão pressupõe um erro. A tese ilusionista denuncia este erro. Acredita-se no que não é. Imputa-se a um fenômeno, a uma conduta, uma causa falsa, ilusória. Isto é, uma causa que não mantém com o comportamento estudado nenhum nexo axiológico. A rigor, ao pressupor um erro, 
a ilusão denuncia a existência de duas causas. Uma verdadeira e ignorada e outra falsa, indevidamente apontada como a verdadeira.

A proposta ilusionista não é recente. Um inventário nada exaustivo nos remete a algumas referências obrigatórias: "L'esprit est le plus souvent la dupe du couer" (La Rochefoucauld), "O coração tem suas razões que a razão não conhece" (Pascal); na sociologia, Pareto vai insistir com as falsas crenças, retomado por Aronson, que aponta a tendência do sujeito social em cobrir de razões ilusórias as crenças e comportamentos de origem afetiva. Por vezes, julga-se próprio um interesse que é, na verdade, da classe dominante (Marx). Da mesma forma, o automatismo e a sugestibilidade de Le Bon e Tarde.

O primeiro traço consistente da expressão "ilusão subjetivista" está em Durkheim nas Règles de la méthode sociologique. Ao definir o fato social como "um conjunto de maneiras de agir, de pensar e de sentir que existem fora das consciências individuais" (...) "dotados de uma potência imperativa e coercitiva em virtude da qual se impõem", Durkheim aponta para a existência de um processo de socialização, no qual a inculcação tem papel importante. Entre Marx e Durkheim, surge o habitus de Bourdieu, assim definido pelo autor:

"Os condicionamentos associados a uma classe particular de condições de existência produzem o habitus, sistemas de disposições duráveis e inter-cambiáveis, estruturas estruturadas predispostas a funcionar como estruturas estruturantes, isto é, enquanto princípios geradores e organizadores de práticas que podem ser objetivamente adaptadas a seus fins sem supor a previsão consciente dos fins e o domínio expresso das operações necessárias para atingi-los, objetivamente 'regulados' e 'regulares' sem ser, de maneira nenhuma, o produto da obediência a regras e, sendo tudo isso, coletivamente orquestradas sem ser o produto da ação organizadora de um chefe de orquestra"15.

Bourdieu concebe a ação não consciente, isto é, que dispensa qualquer cálculo estratégico, bem como o domínio expresso das operações e a previsão consciente dos fins. Isto porque as regras sociais interiorizadas são geradoras de comportamento, produtoras de práticas estratégicas sem uma "ação racional". Assim, dois aspectos nos interessam mais nesta definição: a não- consciência de meios e fins (A) e a possível dimensão estratégica sem cálculo (B).

\section{Habitus e consciência}

É preciso reconhecer a Sartre, sugere Bourdieu, o mérito de dar uma formulação ultra conseqüente da filosofia da ação a todos os que descrevem as práticas como estratégias explicitamente orientadas a fins explicitamente definidos por um projeto livre.

Desta forma, por não reconhecer a existência de disposições duráveis, de esquemas de classificação do mundo interiorizados numa trajetória singular do sujeito no social, Sartre faz de cada ação, pela nadadização do passado, uma confrontação sem antecedentes, portanto sem causa, do sujeito e do mundo.

Para que isto seja possível, a psicologia sartriana exclui toda a presença de não- consciência no projeto original. Para Sartre, este último é exclusivamente constituído por "fins intencionais"16. Crítico declarado deste primado da consciência, Bourdieu contrapõe à intencionalidade espontânea "potencialidades objetivas", isto é, disposições que podem ser atualizadas (no duplo sentido de atualidade e de ato) e em função das quais as práticas sociais se definem. Assim: coisas a fazer e a não 
fazer, a dizer ou a não dizer, em relação a um futuro provável que, contrariamente a um futuro como "potencialidade absoluta" (absolute Möglichkeit), no sentido de Hegel (projetado pelo projeto puro de uma liberdade negativa), se propõe como urgência e imediatismo ${ }^{17}$, tendo a pretensão de advir dispensando qualquer deliberação consciente.

Já no existencialismo, a relação entre o ser da consciência (ser para si) e o ser do fenômeno (ser em si) se objetiva numa unidade (ser no mundo). Esta relação só pode ter como fundamento a consciência, enquanto pura espontaneidade, enquanto vazio ontológico e, portanto, indeterminável. Assim, o sentido das coisas do mundo só pode ser dado a partir da consciência, que é um nada, e não imposto a ela pela própria realidade ou por qualquer outro elemento interno ao sujeito.

Torna-se, assim, para Sartre, uma vez mais inaceitável o conceito bourdieusiano de habitus, já que este pressupõe uma determinação bifásica: num primeiro momento, a observação continuada do real das relações sociais define e redefine disposições duradouras, que deixam traços. Num segundo momento, estas disposições, decorrentes da observação do social, geram comportamento dispensando projeto, cálculo. Ora, nenhuma destas duas etapas seria aceitável, para Sartre, na reflexão sobre o agir do sujeito. Isto é, visando aos fins constitutivos de um projeto deliberado, o homem age com consciência, isto é, estrategicamente.

\section{Estratégia e consciência}

A origem do termo "estratégia" é militar. Trata-se, neste sentido, de um cálculo racional, de um plano, um projeto, que relaciona objetivos refletidamente definidos e os melhores meios para alcançá-los. Assim, como no marketing, os custos e benefícios são conscientemente avaliados a cada momento da operação. As variáveis, que podem afetar direta ou indiretamente o projeto, são ponderadas, na medida de um grau de interferência calculada ou presumida, durante a discussão sobre os procedimentos que constituem a ação.

Essas variáveis, via de regra, são atuantes no momento da execução, isto é, podem produzir efeitos sobre a trajetória dos autores do projeto em direção ao alvo. Em alguns projetos, no entanto, são avaliadas também tendências comportamentais cujas origens, ou causas, escapam ao momento do projeto. São lógicas preestabelecidas segundo as quais, dadas determinadas condições, o agente tenderá a proceder de uma forma e não de outras. Neste caso, a conduta do agente passa a depender menos de um cálculo consciente e mais de disposições incorporadas ao longo de uma trajetória de relações. Aqui nos aproximamos do conceito bourdieusiano de estratégia.

No seu sentido militar ou mercadológico, o conceito de estratégia pressupõe um cálculo consciente e permanente como fundador dos deslocamentos sociais. Bourdieu, evidentemente, não ignora as avaliações conscientes de custos e benefícios. Mas, graças a um repertório de disposições duráveis (mas não imutáveis) já incorporadas, práticas potenciais adaptadas por antecipação a um grande número de situações são capazes de assegurar um rendimento satisfatório de investimentos em um determinado universo. Desta forma, esse operador não consciente de cálculo social permite a orientação nesse espaço sem cálculo. São papéis improvisados cujas manifestações obedecem a um domínio prático que dispensa o pensamento refletido e explícito.

Essas disposições interiorizadas, no entanto, não cobrem a totalidade das situações da vida em sociedade. Mais precisamente, quanto mais a situação experimentada no instante se aproxima de situações análogas para as quais já se definiram disposições de conduta, 
menos se faz necessária a intervenção de uma reflexão consciente. Isto porque estas situações ensejaram, sob a forma de inculcação, percepções e esquemas de classificação e valoração do mundo social vivido. Inversamente, quanto mais a situação se afasta de experiências anteriores, menos as soluções prontas do habitus aprendido e incorporado satisfazem para definir o comportamento a ser tomado.

Alguns analistas de Bourdieu ${ }^{18}$ vêem aqui uma aproximação da liberdade sartriana com o conceito de habitus, em função de suas lacunas. Esta aproximação, que relativizaria a ilusão calculadora do filósofo, a nosso ver, não se sustenta. Afinal, a leitura do livro $\mathrm{V}$ de L'Être et le néant não deixa dúvidas de que a liberdade não significa uma ausência eventual de impedimentos externos e internos para se alcançar o que se quer. A liberdade resumese a definir o que se quer, eleger fins autonomamente e não necessariamente alcançá-los. Isto é, a liberdade independe do êxito do projeto que a objetiva.

Desta forma, não podemos concebêla como determinada por uma eventual lacuna de socialização. Ora, sabemos que para Sartre o limite da liberdade é sua inexorabilidade. Não escolhemos a liberdade. Somos lançados nela, ou seja, "estamos condenados a ser livres". Do contrário poderíamos escolher nossa existência e suas condições materiais. Estaríamos, neste caso, diante de uma liberdade indeterminada, descontrolada.

Por isso, se, para Bourdieu, a ilusão está em considerar-se o marco zero, causa primeira das próprias ações, através de um cálculo refletido sobre cada ato, a ilusão que denunciará Sartre é exatamente oposta.

Sartre e a ilusão determinista ${ }^{19}$

"Será que, no fundo, o que produz medo na doutrina que vou tentar expor não é o fato de que ela deixa uma possibilidade de escolha para o homem?"20

Para Bourdieu, Sartre propõe uma teoria da ação fundada numa liberdade permanente de escolha, num "cálculo propriamente racional" dada uma determinada situação ${ }^{21}$. Essa liberdade de ação se opõe a um senso comum que, segundo o filósofo, crê em determinismos de todos os tipos, isto é, ignora a ausência de quaisquer fundamentos positivos dos valores que guiam suas ações.

A este senso comum, vitimado por uma ilusão subjetivista, Sartre dá o nome de falsificação existencial. Em passagem contundente, o autor denuncia que "estas realidades gelatinosas são vagamente povoadas por uma consciência supraindividual que um organismo vergonhoso procura encontrar, contra qualquer evidência, neste campo rude, complexo, mas insofismável da atividade passiva onde há organismos individuais e realidades materiais inorgânicas"22.

Uma existência assim falsificada coloca-se sob o registro do que o filósofo denomina pejorativamente de espírito de seriedade, que toma os valores a partir do mundo e que reside na substantificação tranqüilizadora e coisista dos valores. Como sentencia Sartre: "O homem sério é do mundo e não tem mais nenhum recurso em si; ele nem mesmo concebe a possibilidade de sair do mundo (...). Ele está de má-fé"23.

A consciência de liberdade encontrase, desta forma, para além desse espírito de

seriedade que nos ilude quanto ao fundamento de todo sentido e valor. O caminho que a ela conduz passa pela adoção de uma postura reflexiva que nos revela a liberdade como sendo o "nada de fundamento", no qual e desde o qual todo sentido e todo valor devem ser sustentados.

Dada a ausência de todo fundamento, Sartre relativiza as condições materiais que presidem qualquer ação. Poderíamos 
dizer que nega a condição, admitindo apenas uma influência situacional, pela liberdade do projeto original. Assim sendo, a liberdade sartriana se objetiva, assim, "numa escolha incondicionada"24.

Sartre enfatiza que o homem está só, que não tem, nem na frente nem atrás, justificativas ou desculpas. A liberdade sartriana, como observa Bernard Sève, é "ontologicamente leve, mas moralmente pesada"25. A ausência de determinismos confere ao agente a permanente possibilidade de agir autrement ${ }^{26}$. Faculta-lhe, assim, atribuir, solitária e isoladamente, sentido ao mundo que observa, interpretando-o como lhe apraz. Sem nenhum suporte ou apoio, o homem está definitivamente "condenado a inventar o homem".

Em razão disto, para o existencialismo, o homem não pode buscar nele mesmo, nem em disposições incorporadas, nem em esquemas interiorizados, nada que - levará a agir. Isto porque um saber prático gerador de ação pressuporia a existência de um repertório, em função do qual o comportamento observado enquanto mensagem ganha sentido. Pressuporia também que as disposições produzidas pela observação "habitual" de comportamentos sociais gerassem condutas, sem cálculo, dadas condições materiais específicas. Ora, isso tiraria do homem a possibilidade de se definir em permanência.

É preciso lembrar que a filosofia de Sartre é uma filosofia da subjetividade, tributária do cogito cartesiano. O sentido do mundo só se constitui para Sartre pela consciência ${ }^{27}$, que se constitui ela mesma como não sendo deste mundo. Assim, a nadadização é, em alguma medida, a transcendência. Mas essa nadadização, isto é, no processo do "ser" em direção à transcendência, a possibilidade de máfé, como veremos, está sempre presente. Isto porque a consciência do homem é ambígua.

Esta ambiguidade provém da tensão entre a facticidade e a transcendência. A facticidade é o que é dado (o corpo no mundo) e a transcendência é a saída fora de si, além de uma condição dada de existência. A facticidade e a transcendência são dois extremos entre os quais temos tendência a ser o que não somos, être ce que l'on n'est pas ${ }^{28}$.

Assim, ao identificarmos uma fonte cartesiana da filosofia de Sartre, destacamos uma recomendação comum de distanciamento de todos os nossos habitos de pensamento, e a dúvida como objetivação permanente de uma ruptura com o passado. A conversão existencialista do cogito reside na relação com a liberdade que mantém o sujeito.

Sartre, nas Situations I, destacará o cogito como fundamento da liberdade que define a existência: "Descartes compreendeu perfeitamente que o conceito de liberdade consistia na exigência de uma autonomia absoluta, que um ato livre era uma produção absolutamente nova (...) e que, conseqüentemente, liberdade e criação eram uma só coisa"29.

A concepção cartesiana da liberdade como poder absoluto de começar, de decidir sobre a falsidade e a veracidade das coisas, face a um Deus bom que não se engana, exprime também, como destacará Sartre, "a realidade humana"30. Para SaintSernin, Sartre adota, de forma integral, o conceito cartesiano de liberdade de criação e de ação. Mas ao invés de considerá-la outorgada ao homem (por Deus), ele a toma como invenção humana projetada em um Outro, que ele denomina Deus. Esta invenção, como traço fundamental do poder de pensar e de agir, está no âmago da liberdade ${ }^{31}$.

Ora, o conceito bourdieusiano de habitus rompe com a filosofia cartesiana da consciência e, ao mesmo tempo, permite evitar a alternativa restritiva entre o determinismo causal e a determinação racional ${ }^{32}$. Desta forma, a compreensão da crítica de Bourdieu a Sartre depende de uma análise das noções de consciência, 
de projeto original, de responsabilidade universal e de má-fé.

Assim, encontramos em Sartre três níveis de consciência que se contrapõem decisivamente ao saber prático bourdieusiano. A consciência de um projeto original, isto é, de um agir para o futuro $(A)$, a consciência de um engajamento universal da ação (B) e, finalmente, a consciência de um agir de má-fé $(C)$.

\section{Consciência do agir para o futuro}

A ação, para Sartre, é livre, obedece a um cálculo custo $x$ benefício, visando a um fim que também é livre. Assim, o fundamento da ação está no futuro, naquilo que livremente se almeja. O homem é, antes de tudo, o que se joga em direção ao futuro, e que é consciente ao agir (custo) de se projetar em direção ao futuro (benefício). Em outras palavras, o benefício futuro, imaginado no instante da ação, enquanto efeito produzido por esta ação (custosa, por definição, porque em ruptura com a inércia), legitima-a, tornando-a aceitável, justificável e até, em alguns casos, inexorável.

Assim, para o existencialismo sartriano, só o efeito da ação, livremente projetado, pode legitimá-la. Isto é, a ação custosa é vista como justificável no instante do projeto ou da execução pela expectativa, contemporânea deste projeto ou desta execução, de um efeito benéfico futuro. Saliente-se que o fundamento existencialista da ação não está no futuro e sim na expectativa instantânea de um efeito futuro.

Esta questão da relação do tempo com o fundamento da ação também é tema central da reflexão sobre o conceito de habitus. Afinal, este último é definido em função da história individual, da singularidade da trajetória social do indivíduo, isto é, do conjunto de posições/ relações experimentadas nos universos específicos a que pertenceu.

Bourdieu, criticando as distintas propostas subjetivistas fundamentadas no pensamento de Sartre, observa que elas ignoram "a história individual e coletiva dos agentes através da qual as estruturas de preferências que os habitam se constituem, numa dialética temporal complexa com as estruturas objetivas que as produzem e que elas tendem a reproduzir"33.

Assim, o habitus não é o destino, como sugerem alguns. Sendo o produto da história, é um sistema de disposições aberto, que está permanentemente à mercê de experiências novas e, portanto, permanentemente afetado por elas. "O agente social, enquanto for dotado de um habitus, é um individual coletivo ou um coletivo individualizado pelo fato da incorporação. O individual, o subjetivo, é social, coletivo. O habitus é subjetividade socializada, transcendental histórico cujas categorias de percepção e de apreciação (os sistemas de preferência) são o produto da história coletiva e individual ${ }^{34}$."

Desta forma, a relevância do passado no agir do presente, para Bourdieu, passa por um estágio primeiro que é o da própria visão do mundo. Isto é, o agente social estará inclinado a classificar a realidade que experimenta sensorialmente em função de disposições moldadas através das experiências do passado. Assim, todo agir social será classificado em função de um repertório valorativo de comportamentos construído através de observações anteriores.

Assim, o fundamento da ação gerada pelo habitus também é contemporâneo da ação. Não mais enquanto projeto e expectativa de efeito futuro (ainda não materializado no instante da ação), como no existencialismo, mas enquanto atualização das disposições de agir aprendidas e incorporadas durante a trajetória do indivíduo na sociedade, isto é, no passado, numa experiência social passada (já sem existência material).

A influência deste passado através do habitus já constituído não elimina a dimensão dialética no confronto com a 
realidade. Isto é, da mesma forma que o real é classificado em função de esquemas de classificação já existentes, estes estão permanentemente sendo atualizados por novas experiências, respeitados os limites definidos pelo saber prático já constituído.

Assim, o habitus, enquanto fluxo em atualização, nem congela no indivíduo esta ou aquela visão de mundo já estruturada, nem permite uma revolução de representações e critérios de classificação a cada segundo. Isto porque os limites da racionalidade e da percepção do real não decorrem só de uma limitação natural, mas são inerentes ao caráter restritivo de toda trajetória e posição num universo social ${ }^{35}$. Talvez estejamos aqui no ponto em que a sociologia de Bourdieu e a filosofia de Sartre mais se afastam.

Desta maneira, este último, analisando as teses deterministas de um sociologismo emergente, insiste que, embora não haja ação sem motivo, "nada pode garantir que o motivo seja causa do ato"36. Afinal, pergunta Sartre, como pode o passado, que já passou, ter tanta força? Isto é, como pode algo que não tem existência material assumir papel de causas de ações concretas (que têm existência material)? Bourdieu responderia que o passado enquanto tal não produz efeitos. No entanto, enquanto ainda não é passado, num processo educativo permanente e singular para cada indivíduo, inculca disposições que, sendo duráveis, agirão na presencialidade da sua existência.

Assim, enquanto para Bourdieu a singularidade de cada agente social se objetiva numa particular combinação entre uma trajetória atualizada por disposições e uma posição sempre presente e mutável num universo social específico, para Sartre, a singularidade do "ser" está na forma única de isolamento em relação ao passado, isto é, na nadadização garantidora da liberdade do projeto original.

Em suma, se o ser é pensável a partir do tempo, se é temporal ou depende da temporalidade, não é o passado que
Ihe dá sentido ou causa. Como observa Bernard-Henri Lévy, comentando Sartre, o passado "está longe de alimentar o futuro, de futurizar o tempo, insuflando sobre ele a sua energia" ${ }^{37}$. É exatamente o contrário que se produz: o futuro outorga sua força ao passado. Causa final em triunfo sobre a causa eficiente.

Quando se toma consciência do eu através da pergunta "que sou eu?", "há uma noção que sempre escapa, é a noção do começo"38. Em La nausée ${ }^{39}$ Sartre observa: "É isso o tempo, o tempo completamente nu, chega lentamente na existência, se faz esperar, e quando chega nos desesperamos porque nos damos conta que já se encontrava lá, há muito tempo". Isto é, se para Sartre só podemos perceber o tempo no ineditismo da sua atualidade, para Bourdieu a consciência temporal do agir só surge na eventualidade de um cálculo necessário, da ausência de uma solução mais ou menos pronta.

Assim, no caso de uma reflexão sobre o comportamento virtuoso, mais especificamente desinteressado, enquanto para o filósofo só a ruptura com o passado, isto é, a ação livre decorrente da contingência, pode fundamentar qualquer ação verdadeiramente virtuosa (por exemplo, a ação não utilitarista/egoísta), para o sociólogo esta última só é possível em função do encontro de um habitus, enquanto história passada feita corpo presente, e de um universo social onde o desinteresse seja recompensado ${ }^{40}$.

Este tema do projeto que neantisa o passado é um dos mais freqüentes na obra literária de Sartre; é esta liberdade inerente à possibilidade de refutação do passado que torna os personagens tão sujeitos a reviravoltas, isto é, tão pouco determinados por disposições duráveis, garantidoras de uma certa coerência do agir em situações análogas. Assim, em "Huis clos" ${ }^{1}$, Garcin suplica às forças do inferno para vir abrir a porta; ao vê-la aberta fica-lhe facultada a entrada. Brutalmente, no entanto, ele recua, ele dá meia-volta, ele "renuncia". Da 
mesma forma, Erostrate ${ }^{42}$, preso no toalete de um café na rua Odessa, perseguido pela polícia, sabe que lhe resta uma bala no revólver para matar-se. No entanto, ele quer certificar-se se sua vítima estava realmente morta, abrindo a porta para a polícia.

Para Sartre, a escolha só é dirigida para o futuro porque a neantização é apenas o dépassement (ir além) em relação ao passado. Eis uma das grandes diferenças com Bourdieu e com Merleau-Ponty. Ao rejeitar a noção de hábito (destacada por contemporâneos como Bergson ${ }^{43}$, Ricoeur ${ }^{44}$ ou MerleauPonty $^{45}$, que insistem na importância do passado), Sartre enfatiza o futuro, porque só podemos, segundo ele, descobrir a importância do passado em função de um projeto.

Para que a liberdade efetivamente desautorize as determinações que, atuantes sobre a realidade humana, pretendem coisificá-la e inseri-la em uma cadeia causal, ela deve instaurar uma fissura entre passado e presente, entre as condições determinantes dos comportamentos humanos e os comportamentos eles mesmos. Tais fissuras não são nem podem ser constituídas pelo ser, pois este necessariamente insere-se na cadeia da causalidade universal. O ser não escapa ao determinismo: somente ao nada é dado produzir uma falha na plenitude ontológica; e somente a liberdade pode trazer o nada ao núcleo do ser.

Isto significa que Sartre resgata a possibilidade de ruptura como o passado pela consciência, "de se despregar dele para poder considerá-lo à luz de um não ser e para lhe conferir um sentido que ele tem a partir do projeto de um sentido que ele não tem. Em nenhuma hipótese o passado por si mesmo pode produzir um ato"46. Mas a possibilidade de ruptura com o passado tem um preço. A responsabilidade de engajar toda a humanidade num projeto através das opções conscientes e racionais do projeto original.
Consciência de um agir que produz efeitos universais (engajamento de toda a humanidade)

Trata-se da consciência de que ao moldar sua imagem agimos como legisladores do mundo, decidindo como o homem deve ser. Assim, tudo se passaria como se a humanidade inteira tivesse os olhos voltados para aquele que age e, ainda mais, tomasse esta ação como regra. Afinal, para Sartre, o homem ao agir não só realiza livremente seu projeto original, mas define toda a humanidade através da ação. Isto porque, "ao se escolher, escolhe todos os homens". A ação do homem define, desta forma, um modelo de homem. Escolher é dar a ver uma escolha a toda a humanidade, é afirmar um valor em detrimento de outros, é reduzir uma contingência produzindo efeitos universais. É gerar expectativas não só do que pretendo, do meu projeto, mas do que entendo por modelo de comportamento para todos.

Assim, existimos ao dar a ver nossa ação, enquanto parte visível o observável do ser, a toda a humanidade. Por isso, para Sartre, existimos ao mesmo tempo que moldamos a nossa imagem que é válida não só para os que estão no nosso circuito direto de relações interpessoais, mas "para todos de nossa época"47.

Sartre dá o exemplo da monogamia. Ele observa que querer se casar (fato individual), ter filhos, ainda que esta decisão dependa unicamente de uma decisão pessoal, de uma paixão, ou de um desejo, através dela engaja-se toda a humanidade na via da monogamia. Sartre estende a responsabilidade individual em função do alcance da decisão tomada.

Dados esta liberdade do projeto original e o caráter universal que assume cada ação, Sartre desconsidera a pertinência, em nível macrossociológico, de explicações mais ou menos mecanicistas 
como a teoria do reflexo, do bloco histórico ou ainda (no caso de que tivesse tido acesso a ela) da teoria dos campos de Bourdieu. Assim, enfatiza que "o que o existencialismo busca mostrar é a ligação do caráter absoluto do engajamento livre, pelo qual cada homem se realiza, realizando um tipo de humanidade, engajamento sempre compreensível em qualquer época e por qualquer um, e a relatividade do conjunto cultural que pode resultar de semelhante escolha"48.

Naturalmente, Bourdieu não despreza os efeitos sociais de toda ação enquanto definidora de posições sociais, de deslocamentos no interior deste ou daquele universo social, de estratégias de conservação ou de subversão da estrutura destes universos. Assim, a ação age sobre o social e como tal se constitui em matériaprima de toda reflexão sociológica. Mas, ao se dar a ação social como objeto, Bourdieu a inscreve numa lógica causal, na qual a materialidade da conduta é inseparável das condições materiais que facultaram sua existência. Assim, a anterioridade do social, do fato social imperativo e independente das consciências individuais, é regra metodológica incompatível com o primado sartriano de um sujeito que age livremente numa arena e, observado por todos, define espetacularmente o homem.

Assim, se Sartre resgata a dignidade do sujeito, distinguindo-o "de um couveflor" 49 , engaja a humanidade inteira em qualquer um de seus atos, condenando-o à definição e redefinição permanentes do que é o próprio homem. Essa responsabilidade de definir uma conduta para mim e para o universo é um fardo que, para Sartre, o homem nem sempre assume. Surge assim o conceito sartriano de má-fé.

\section{Consciência de um agir de má-fé}

A má-fé sartriana é a recusa do caráter ou o efeito universal de nossa conduta para reduzir a responsabilidade do engajamento e, com isso, reduzir a angústia que dela advém. Como observa Sartre, só escapamos do pensamento inquietante, de sermos responsáveis por todos, através de uma má-fé ${ }^{5}$. A má-fé é definida num prisma moral enquanto um engano, uma mentira para si mesmo, porque dissimula a total liberdade do engajamento. Na máfé sartriana, reúne-se na mesma pessoa o enganador e o enganado, quem ilude e 0 iludido ${ }^{51}$. A ilusão a que nos referimos aqui não se confunde com "a ilusão subjetivista" a que se referem Durkheim e Bourdieu para indicar a confusão entre o "fato social" objetivamente externo às consciências e a sua interiorização. Isto porque, neste caso, o iludido crê, como em qualquer golpe de violência simbólica, no que não é. Na má-fé de Sartre, o enganado só pode estar plenamente consciente do engano que ele mesmo se outorga. Como explica Gabriel Marcel ${ }^{52}$, comentando Sartre, a má-fé consiste numa certa arte de formar conceitos contraditórios, unindo neles uma idéia e o contrário desta idéia. Ela só é possível, ainda segundo Marcel, porque a estrutura do ser humano consiste na obrigação constante de se fazer ser o que é, isto é, pela definição do dever ser através de um processo ininterrupto de escolhas.

Sartre define a má-fé como sendo uma forma de decisão de fuga desta responsabilidade universal dos atos. É a tentativa involuntária de se esconder de si mesmo, a realização de uma falsa unidade de si aos seus próprios olhos e aos olhos dos outros. Nessa seqüência lógica, para Sartre, todo analista que sugere qualquer tipo de determinismo limitante da liberdade de ação, isto é, algum tipo de causalidade que envolva a conduta humana, é um analista de má-fé. Assim definiria Sartre o conceito de habitus, bem como grande parte dos pressupostos da teoria da ação de Pierre Bourdieu.

Assim, como pudemos observar, a consciência como intencionalidade, a nadadização do passado, a liberdade 
de um agir livre, o projeto original com fins conscientemente deliberados, o engajamento universal pela ação, a angústia e a má-fé que dele decorrem são alguns dos conceitos existencialistas objetos de crítica ao longo da teoria sociológica de Pierre Bourdieu. Sem incorrermos na solução metodológica cômoda da justaposição Sartre $x$ Bourdieu, destinando uma parte a cada teoria e concluindo com a constatação de antagonismos e eventuais aproximações, optamos por contrastar conceito a conceito os pressupostos que justificam e ensejam tão importante distanciamento entre ambas concepções .

\section{Notas}

1 BRUN, J. "La mort du sujet et Auschwitz". In Penser le sujet aujourd'hui (Colloque de CerisY). Paris, Méridiens Klincksieck, 1988, p. 79.

2 As críticas mais contundentes estão concentradas nos clássicos da primeira fase da produção de Bourdieu, sobretudo: Le sens pratique, La distinction, Esquisse d'une théorie de la pratique e na entrevista de vulgarização de alguns de seus principais conceitos publicado com o título de Réponses.

3 Termo usado para traduzir néantisation, expressão derivada da palavra néant (traduzida por "nada") constitutiva do título da principal obra filosófica de Sartre, L'Être et le néant.

4 Para aplicar à doutrina de Bourdieu, ou a de qualquer outro autor, suas próprias indicações metodológicas, é preciso preliminarmente reconstituir o espaço de contingências, de possibilidades, em meio às quais o "projeto intelectual" em questão objetivou-se. É indispensável também identificar as posições ocupadas pelo seu autor no campo específico de produção em que se inscreve, identificando, assim, a singularidade de sua trajetória neste espaço, bem como os efeitos de reacomodação no campo a cada nova tomada de posição.

5 Um trabalho com estas características procura fazer Annie Cohen-Solal em Sartre. Paris, Folio, 1985.
6 Em relação à posição de dominação ocupada por Sartre no campo filosófico francês, Bourdieu relata iniciativas de resistência, isto é, estratégias de subversão. Entre elas "uma história da filosofia estreitamente ligada à história das ciências, representada por duas grandes obras: Dynamique et métaphysique leibniziennes, de Martial Guéroult (...) e Physique et métaphysique kantiennes de Jules Vuillemin; uma epistemologia e uma história das ciências representadas por Gaston Bachellarde, Georges Canguilgem e Alexandre Koyré". BOURDIEU, P. Méditations pascaliennes. Paris, Seuil, 1997, p. 50.

7 BOURDIEU, P. Méditations pascaliennes, op. cit. p. 50.

8 SARTRE, J-P. L'existentialisme est un humanisme. Paris, Nagel, 1970, p. 10.

9 SARTRE, J-P. L'existentialisme est un humanisme. op. cit. p. 63.

10 SARTRE, J-P. La transcendance de l'ego. Paris, Librairie philosophique J. Vrin, 1965, p. 85.

11 LUKACS, G. Existentialisme ou marxisme. Paris, Nagel, 1961.

12 Expressão usada por Bourdieu na famosa nota 33 do Esquisse d'une théorie de la pratique, op. cit. p. 248.

13 Denominações usadas por Sartre para identificar seus principais adversários, sobretudo em L'existentialisme est un humanisme.

140 termo calculadora está grafado em itálico porque não está adjetivando ilusão e sim a teoria da ação considerada ilusória.

15 BOURDIEU, P. Le sens pratique. Paris, Minuit, 1980, pp. 88-89.

16 Sartre não pode aceitar o conceito de inconsciente, posto que este conduz a um modelo no qual a consciência aparece, não como instituidora de significatividade, mas como recebendo toda a significação, quer do social como quer o sociologismo, quer do inconsciente, como quer a psicanálise.

17 Essa urgência e imediatismo se devem à necessidade de economia de tempo na prática social, isto é, a uma 
rapidez crescente das exigências do agir social. Por isso, 0 habitus, por dispensar o cálculo, é um princípio de economia de tempo da ação.

18 Destaca-se aqui o trabalho de HONG, S-M. Habitus, corps et domination. Paris, L'Harmattan, 1999.

190 adjetivo determinista se encontra grafado em itálico porque, como na ilusão calculadora, não estão adjetivando ilusão e sim a teoria da ação considerada ilusória.

20 SARTRE, J-P. L'existentialisme est un humanisme. Paris, Nagel, 1970, p. 15.

21 Esta dimensão de "cálculo racional" destacada nas críticas bourdieusianas é, em alguns momentos, relativizada por Sartre, como nos trechos de L'Être et le néant aludidos abaixo. Assim, as "intenções pré-reflexivas" de um certo "querer" ou "mudança de direção espontânea" (p. 41), que dão sentido ao vivido, "não tem finalidade nem refletida (p. 34) nem inconsciente (p. 52)" mas fornecem uma "resposta adaptada a uma situação" (p. 36).

22 SARTRE, J-P. Critique de la raison dialectique. Paris, Gallimard, 1960, p. 305.

23 SARTRE, J-P. L'Être et le néant. op. cit. p. 669.

24 HUISMAN, D. Histoire de l'existentialisme. Paris, Nathan, 1997, p. 92.

25 SÈVE, B. "Sartre ou le tourbillon de la liberté". In Les Philosophes de Platon à Sartre. Paris, Hachette, 1985, p. 516.

26 Termo sartriano não traduzido pela falta de advérbio equivalente e que significa "de outra forma".

27 Assim, como observa AMARAL VIEIRA, R. A. em Sartre e a revolta do nosso tempo. Rio de Janeiro, Forense, 1967, p. 51, "Sartre subordina o mundo ao pensamento, condicionando a consciência social à individual".

28 "É preciso repetir aqui o que já sabemos desde Descartes: uma consciência reflexiva nos fornece dados absolutamente certos (...) 0 ato da reflexão tem, portanto, um conteúdo imediatamente certo que passaremos a chamar a essência da imagem". SARTRE, J-P. L'Imaginaire. Paris, Gallimard, 1948, p. 13-14.
29 SARTRE, J-P. Situations I. Paris, Gallimard, 1947, p. 334.

30 Esta relação da liberdade com o Deus cartesiano é expressamente destacada por Sartre: "O Deus de Descartes é o mais livre dos Deuses que já forjou 0 pensamento humano". SARTRE, J-P. Situations I. op. cit. p. 403.

31 SAINT-SERNIN, B. "On entre dans un mort comme dans un moulin". In Temps modernes. N. 531/533. V. I, 1990, pp. 164-187.

32 BOURDIEU, P. "Le champ économique". In Actes de la recherche en sciences sociales. N. 119, set/1997, p. 62.

33 BOURDIEU, P. Réponses. Paris, Seuil, 1992, p. 99.

34 BOURDIEU, P. "Le champ économique". In Actes de la recherche en sciences sociales. op. cit. p. 62.

35 BOURDIEU, P. "Le champ économique". In Actes de la recherche en sciences sociales. N. 119, set. 1997, pp. 4866.

36 MOUTINHO, L. D. Sartre: existencialismo e liberdade. São Paulo, Moderna, 1995, p. 61.

37 LÉVY, B-H. Le siècle de Sartre. Paris, Grasset, 2000, p. 170.

38 CAMPBELL, R. Jean-Paul Sartre ou une littérature philosophique. Paris, Pierre Ardant, 1945, p. 47.

39 SARTRE, J-P. La nausée. Paris, Gallimard, 1938, p. 49.

40 Sobre a reflexão sociológica de Bourdieu a respeito da possibilidade de uma ação desinteressada, ler BOURDIEU, P. Raisons pratiques. Paris, Seuil, 1994, pp. 147-167.

41 SARTRE, J-P. Huis clos. Paris, Gallimard, 1944.

42 SARTRE, J-P. Le mur. Paris, Gallimard, 1939.

43 BERGSON. Matière et mémoire. Paris, PUF, 1997.

44 RICOEUR, P. Philosophie de la volonté. Paris, Aubier, 1968. 
45 MERLEAU-PONTY, M. Phénomenologie de la perception. Paris, Gallimard, 1967.

46 SARTRE, J-P. L'Être et le néant. Paris, Gallimard, 1943, p. 511.

47 SARTRE, J-P. L'existentialisme est un humanisme. op. cit. p. 26.

48 SARTRE, J-P. L'existentialisme est un humanisme. op. cit. p. 71.

49 Isto é, o sujeito não é simples objeto de determinismos anteriores.

500 conceito de má-fé é apresentado como fundador por muitos campos de saber que tem a filosofia de Sartre como objeto. Assim, a metafísica, a psicologia, a teoria da moral e a antropologia. Esta multipresença se deve à relevância do conceito para a compreensão do existencialismo do autor, bem como aos vários sentidos que 0 autor confere ao termo nos distintos momentos de sua obra.

51 Sobre esta confusão ler BURDZINSKI, J-C. Má-fé e autenticidade. ljuí, Unijuí, 1999, pp. 37-38.

52 MARCEL, G. L'existence et la liberté humaine chez JeanPaul Sartre. Paris, Librairie philosophique J. Vrin, 1981, p. 55.

\section{Referências}

AMARAL VIEIRA, R. A. Sartre e a revolta do nosso tempo. Rio de Janeiro, Forense, 1967.

BERGSON. Matière et mémoire. Paris, PUF, 1997.

BOURDIEU, P. Le sens pratique. Paris, Minuit, 1980.

. "Le champ économique". In Actes de la recherche en sciences sociales. N. 119, set/1997, p. 62.

. Méditations pascaliennes. Paris, Seuil, 1997.

Raisons pratiques. Paris, Seuil, 1994.
Réponses. Paris, Seuil, 1992.

BRUN, J. "La mort du sujet et Auschwitz". In Penser le sujet aujourd'hui (Colloque de CerisY). Paris, Méridiens Klincksieck, 1988.

BURDZINSKI, J-C. Má-fé e autenticidade. ljuí, Unijuí, 1999.

CAMPBELL, R. Jean-Paul Sartre ou une littérature philosophique. Paris, Pierre Ardant, 1945.

COHEN-SOLAL, A. Sartre. Paris, Folio, 1985.

HONG, S-M. Habitus, corps et domination. Paris, L'Harmattan, 1999.

HUISMAN, D. Histoire de l'existentialisme. Paris, Nathan, 1997.

LÉVY, B-H. Le siècle de Sartre. Paris, Grasset, 2000.

LUKACS, G. Existentialisme ou marxisme. Paris, Nagel, 1961.

MARCEL, G. L'existence et la liberté humaine chez Jean-Paul Sartre. Paris, Librairie philosophique J. Vrin, 1981.

MERLEAU-PONTY, M. Phénomenologie de la perception. Paris, Gallimard, 1967.

MOUTINHO, L. D. Sartre: existencialismo e liberdade. São Paulo, Moderna, 1995.

RICOEUR, P. Philosophie de la volonté. Paris, Aubier, 1968.

SAINT-SERNIN, B. "On entre dans un mort comme dans un moulin". In Temps modernes. N. 531/533. V. I, 1990.

SARTRE, J-P. Critique de la raison dialectique. Paris, Gallimard, 1960.

Huis clos. Paris, Gallimard, 1944.

La nausée. Paris, Gallimard, 1938.

La transcendance de l'ego. Paris, Librairie philosophique J. Vrin, 1965.

L'Être et le néant. Paris, Gallimard, 1943. 
1970.

L'existentialisme est un humanisme. Paris, Nagel,

Le mur. Paris, Gallimard, 1939.

L'Imaginaire. Paris, Gallimard, 1948.

Situations I. Paris, Gallimard, 1947.

SÈVE, B. "Sartre ou le tourbillon de la liberté". In Les

Philosophes de Platon à Sartre. Paris, Hachette, 1985. 